\title{
THE GENUS OONOPS (ARANEAE, OONOPIDAE) IN PANAMA AND \\ THE WEST INDIES. PART 2
}

\author{
By Arthur M. Chickering \\ Museum of Comparative Zoology
}

This is the seventh paper in the series planned for publication on the various genera in the Family Oonopidae in Central America and the West Indies. It is the second paper on the genus Oonops and deals with this genus as it is now known in the Bahama Islands and the Virgin Islands, both British and American.

Attention is called to the preface of Part I on the genus Oonops. In that paper I have treated the species at present known from Panama, Costa Rica, Trinidad, W. I. and Curaçao, Netherlands Antilles. And I have also given a resumé of the features of the genus as now understood from the study of collections from the general region under consideration at present.

I am endebted to Dr. W. J. Gertsch, formerly Curator of Arachnida in the American Museum of Natural History, and to Dr. J. A. L. Cooke, now Associate Curator of Arachnida in the same institution, for the loan of a very helpful collection of Oonops from the Bahama Islands.

The genus Oonops was not included in the collection of spiders from the Virgin Islands studied by Dr. Petrunkevitch (1926). According to my present view, Telchius placidus Bryant must be placed in the genus Oonops but for reasons given later a new name must be assigned to it. This now seems to have been the only species recorded from the Virgin Islands until the present time. It now seems quite clear that the genus is fairly abundant in the Bahama Islands and the Virgin Islands, both British and American and probably in neighboring islands as well. I have had a rather large collection from this region with which to work. As often happens in the study of small and fragile specimens difficulties have often arisen to plague the investigator. For several months after resuming the study of this genus from the region under immediate consideration it seemed likely that the recognition of approximately a dozen species would be necessary. As the work progressed, however, I became convinced that several of these should be combined into two species with a rather wide distribution and including some very puzzling variations. At the present time, therefore, I can with reasonable certainty only recognize the following species from this region: Oonops balanus nomen novum; Oonops bermudensis Banks; Oonops castellus sp. 
nov.; Oonops endicus sp. nov.; Oonops gertschi sp. nov.; Oonops ronoxus sp. nov. A few specimens are left unplaced because of uncertainties regarding their status.

\section{Genus Oonops Templeton, I835 Oonops bermudensis Banks}

Oonops bermudensis Banks, 1902: 269, fig. 1. The female holotype was from the Bermuda Islands but efforts to locate it have been completely unsuccessful. Simon, 1903: 983 ; Petrunkevitch, 1911: 127; Roewer, 1942: 278; Bonnet, 1958: 3189.

Simon (1903) was uncertain about the generic status of this species. Banks' Figure I, showing the epigynal area, suggests that it belongs to Heteroonops spinimanus (Simon).

\section{Oonops balanus nomen novum}

Figures I-I I

Telchius placidus Bryant, 1942: 323, figs. 3-4. The male holotype from St. Croix, U. S. Virgin Islands is in the Museum of Comparative Zoology, Harvard University, examined. The name Oonops placidus is preoccupied by Dalmas, 1916.

The male holotype is badly dismembered and only one palp is still available for study. I feel fairly confident, however, that the species belongs in the genus Oonops where it is placed here.

Numerous specimens believed to belong to this genus from South Bimini, Bahama Islands, all three U. S. Virgin Islands and Virgin Gorda, British Virgin Islands were for a considerable length of time regarded as belonging to several different new species. Repeated reexaminations have finally convinced me that the safest treatment in our present state of knowledge of the genus Oonops is to combine them all into one species as presented here. As usual, all six eyes are nearly of the same size but the outlines are often difficult to discern clearly. Some differences in respect to size and placement have been noted among the specimens from different islands but differences have also been observed among the specimens from a single island. The height and general shape of the carapace vary somewhat also, but not significantly from the taxonomic viewpoint. I have placed the greatest emphasis on the features of the male palpal tarsus. This organ also shows some variation among the specimens from different localities but these now seem to fall well within the limits of variation in a single widespread species. The appearance of the palpal tarsus, especially the embolus, depends as much upon the angle of vision as upon any other factor. Figures I-I I show parts of the holotype, female paratype and fairly recently collected specimens from St. Croix, V. I., South Bimini, Bahama Islands and Virgin Gorda, British Virgin Islands. 

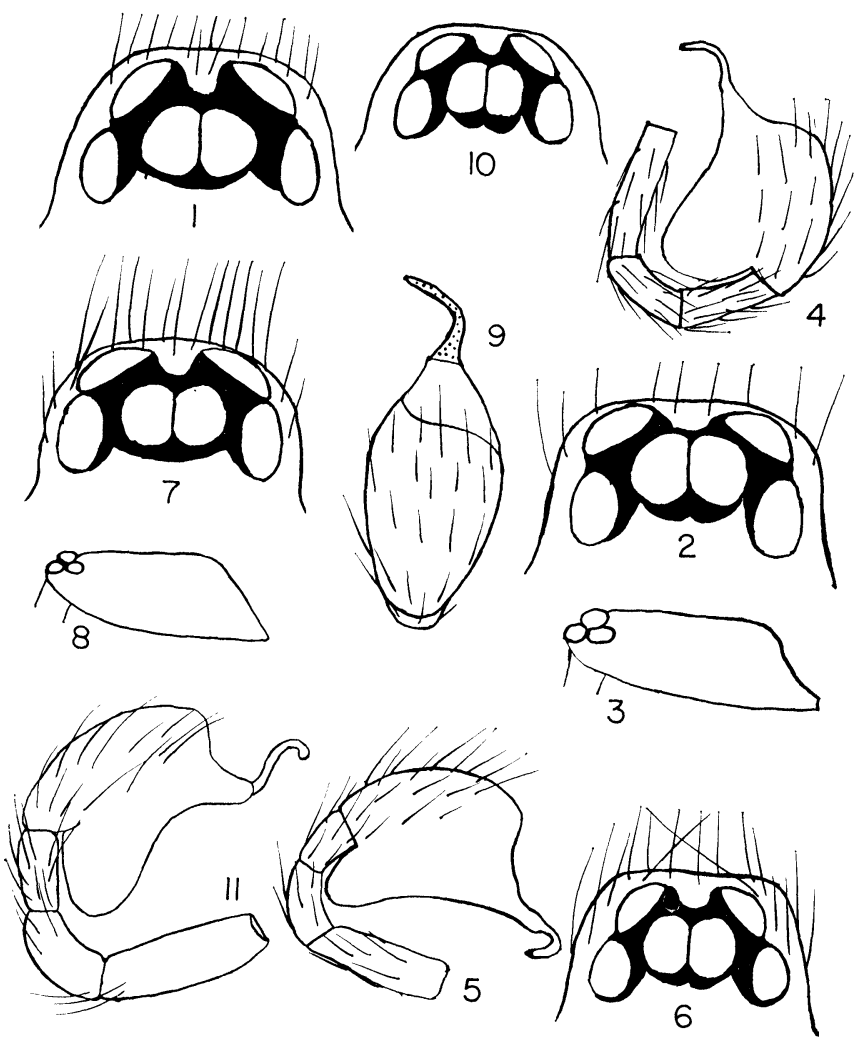

Figs. 1-11. Oonops balanus nomen novum. Figs. 1-2. Eyes of male holotype and female paratype, respectively; viewed from above. Fig. 3. Carapace of male holotype; left lateral view. Fig. 4. Palp of male holotype; lateral view. Figs. 5-6. Left palp of male, prolateral view and eyes of male from above, respectively; from St. Croix, V. I., Sept., 1966. Figs. 7-8. Eyes of male from above and carapace of male, left lateral view, respectively; from Virgin Gorda, B. V. I., Aug., 1966. Fig. 9. Right palpal tarsus of male, nearly dorsal view; from Virgin Gorda, B. V. I., Aug., 1966. Figs. 10-11. Eyes of male from above and left palp of male, prolateral view, respectively; from So. Bimini, Bahama Ids., 1951.

Diagnosis. I think there will be general agreement among taxonomists that it is very difficult to determine relationships among species recognized in this genus. This species appears to be most closely related to Oonops secretus Gertsch from southern Texas and Oonops tenebus sp. nov. from the Panama Canal Zone. The features 
of the male palp, the eyes, shape of the carapace all seem to establish it as a valid species of the genus Oonops.

Records. Numerous specimens of this species are now before me from the following localities: So. Bimini, Bahama Islands, May, 195 I (W. J. Gertsch, M. A. Cazier, C. and P. Vaurie); April, 1952 (E. Mayr); St. John, U. S. V. I., July, I966 and March, 1970 (H., L. and F. Levi) ; St. Croix, U. S. V. I., Sept., I966; St. Thomas, U. S. V. I., July-August, I966; Virgin Gorda, British Virgin Islands, August, I966. It seems very likely that this species will also be identified from other islands in the West Indies to be considered in Part 3 of this series of papers on Oonops.

Oonops castellus sp. nov.

Figures $12-20$

Holotype. The male holotype is from St. Thomas, U. S. Virgin Islands, February I6, 1964. The name of the species is an arbitrary combination of letters.

Description. Total length $1.65 \mathrm{~mm}$. Carapace $0.79 \mathrm{~mm}$ long; $0.62 \mathrm{~mm}$ wide opposite second coxae where it is widest; $0.39 \mathrm{~mm}$ tall; rises behind PME to opposite posterior border of second coxae and then descends steeply to posterior border (Fig. I2); with a sparse covering of light colored hair; with no definite median thoracic groove or pit; surface smooth and shining. Eyes: six as usual in a fairly compact group; posterior row strongly recurved and occupies nearly five-sixths of width of carapace at that level (Fig. I3). Eyes nearly equal in size but with PME slightly the smallest. ALE separated from one another by nearly seven-eighths of their diameter; subcontiguous to PME and PLE. PME contiguous to one another for nearly one-fourth of their circumference; separated from PLE by nearly one-fourth of their diameter. Height of clypeus hardly discernible but probably about one-half the radius of ALE. Chelicerac, maxillae and lip apparently quite typical of males of the genus and without special modifications (observed on dissected paratype). Sternum: quite convex; scutiform as usual; slightly widest between second coxae but nearly as wide between first coxae; only slightly longer than wide; not extended between fourth coxae which are separated by about their width; surface smooth and shining; without grooves or lobes; with a sparse supply of stiff bristles. Legs: 4213 in order of length; first tibiae and metatarsi have paired ventral spines; second legs appear to have only irregularly placed spines; third and fourth legs with fairly well defined spines. Palp: all segments except the tarsus without special features (Figs. I4-I7). 

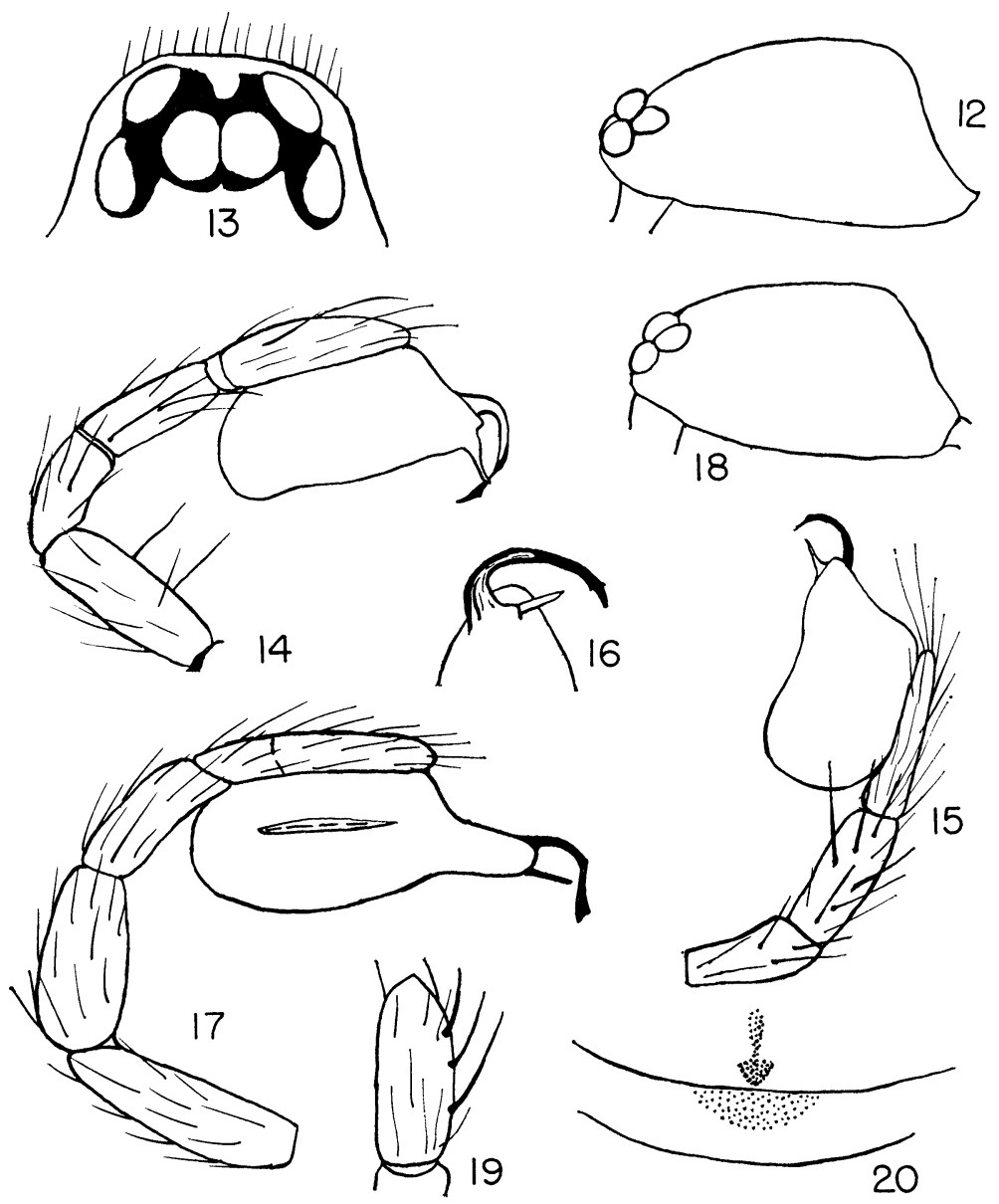

Figs. 12-20. Oonops castellus sp. nov. Fig. 12. Carapace of holotype male; left lateral view. Fig. 13. Eyes of holotype from above. Fig. 14. Left palp of holotype; prolateral view. Fig. 15. Right palp of male paratype; prolateral view. Fig. 16. Tip of right palpal tarsus of male paratype; nearly ventral view; more enlarged. Fig. 17. Left palp of male from St. Croix, V. I.; prolateral view. Fig. 18. Carapace of second female paratype; left lateral view. Fig. 19. Left palpal patella of described female paratype; dorsal view. Fig. 20. Epigynal area of described female paratype from below. 
Abdomen: ovoid; quite typical of males of the genus. Color in alcohol: carapace, sternum, legs and mouth parts all light yellowish; abdomen nearly white with a faint reticulation.

Female paratype. Total length $\mathrm{r} .87 \mathrm{~mm}$. Carapace $0.77 \mathrm{~mm}$ long; $0.64 \mathrm{~mm}$ wide opposite second coxae; $0.35 \mathrm{~mm}$ tall; rises gently from PME to beginning of posterior declivity opposite interval between second and third coxae and then descends to posterior border with a slight concavity just below the middle (Fig. I8). Eyes essentially as in male. Chelicerae, maxillae, lip and sternum: all seem to be essentially as observed in male holotype except that the sternum appears to be slightly grooved and lobed opposite the coxae; third coxae nearly globose, others somewhat elongated; clusters of short bristles occur on weakly developed lobes. Legs: 42 I 3 in order of length; first tibiae with three pairs of ventral spines; first metatarsi with two pairs of ventral spines; second tibiae and metatarsi with two pairs of ventral spines; third and fourth legs also with several spines on tibiae and metatarsi. Abdomen: in general essentially as in male; the epigynal area appears to be obscurely distinctive (Fig. 20); there is some chitinization in the region of epigastric scutum. Color in alcohol: essentially as in male except that the carapace, legs, sternum and mouth parts are somewhat paler; the faint reticulation shows about as in male.

Diagnosis. The species appears to be most closely related to Oonops anoxus sp. nov. from Panama Canal Zone (in press). The features of the male palp together with the eyes and shape of the carapace seem to establish it definitely as a new species.

Records. The described female paratype was taken with the holotype along with numerous other specimens sifted from hay and weed debris. The species is abundant on St. Thomas, V. I. and I have many specimens from localities on this island collected during February, I964 and August, I966. I also have it from St. John, V. I., March, 1964, July, 1966 and March 27, I970 (H. and F. Levi); St. Croix, V. I., March, 1964; Tortola, B. V. I., July 30-Aug. 5, 1966. The species will probably be reported from islands further west in the third paper on this genus.

Note. There are grounds for believing that the male described by Dr. Petrunkevitch as the male of Heteroonops spinimanus (Simon) is in reality a member of Oonops castellus sp. nov. The very poor condition of the specimens from the American Museum of Natural History, used by Dr. Petrunkevitch in his study of Puerto Rican spiders, precludes a definite decision regarding this matter. 


\section{Oonops endicus sp. nov.}

Figures 2I-25

Holotype. The male holotype is from So. Bimini, Bahama Islands, May, I95I ; collected by W. J. Gertsch and M. A. Cazier. It will be deposited in the American Museum of Natural History, New York City. The name of the species is an arbitrary combination of letters.

Description. Total length $\mathrm{I} .89 \mathrm{~mm}$. Carapace $0.88 \mathrm{~mm}$ long; $0.65 \mathrm{~mm}$ wide; $0.26 \mathrm{~mm}$ tall; rises just behind PME and then continues with a slight depression about midway to steep posterior declivity; surface with a sparse covering of dark hairs; with no median fovea or groove. Eyes: six as usual, in a moderately compact group; posterior row recurved and occupies a little more than twothirds of width of carapace at that level (Fig. 2I). Ratio of eyes ALE : PME : PLE $=$ nearly $8: 7.5: 6.25$. ALE separated from one another by nearly seven-eighths of their diameter and separated from PME by nearly one-fourth of their diameter and from PLE by slightly less than this distance. PME contiguous for nearly onethird of their circumference and separated from PLE by slightly more than one fourth of their diameter. Clypeus with several spiniform bristles; height nearly equal to one-fourth the diameter of ALE. Chelicerae: vertical; parallel; with numerous long, spiniform bristles projecting from medial halves; with no special modifications. Maxillae: convergent; narrowed distally and with a terminal cluster of bristles. Lip: wider at base than long; distal end bluntly pointed; without special modifications. Sternum: convex; not grooved or lobed; surface smooth and shining; with numerous bristles; sternal suture procurved; longer than wide in ratio of nearly $4: 3$; bluntly rounded posterior end extended between fourth coxae which are separated by nearly four-fifths of their width. Legs: 4I23 in order of length; spines are almost absent on first and second legs; occasional spines have been observed on third and fourth. Palp: only tarsus with distinctive features (Figs. 22-23); other palpal segments typical of males in the genus. Abdomen: essentially typical of males of the genus; region of the epigastric scutum and genital area very lightly chitinized; genital region, so prominent in the female, is barely indicated here. Color in alcohol: carapace, sternum, legs and mouth parts yellowish with variations; ocular region with a moderate amount of pigment essentially as shown in Figure 2I; abdomen nearly white but with scutal regions slightly yellowish.

Female paratype. Total length $2.2 \mathrm{~mm}$, exclusive of the extended spinnerets. Carapace $0.88 \mathrm{~mm}$ long; $0.62 \mathrm{~mm}$ wide opposite posterior border of second coxae where it is widest; $0.33 \mathrm{~mm}$ tall; other- 

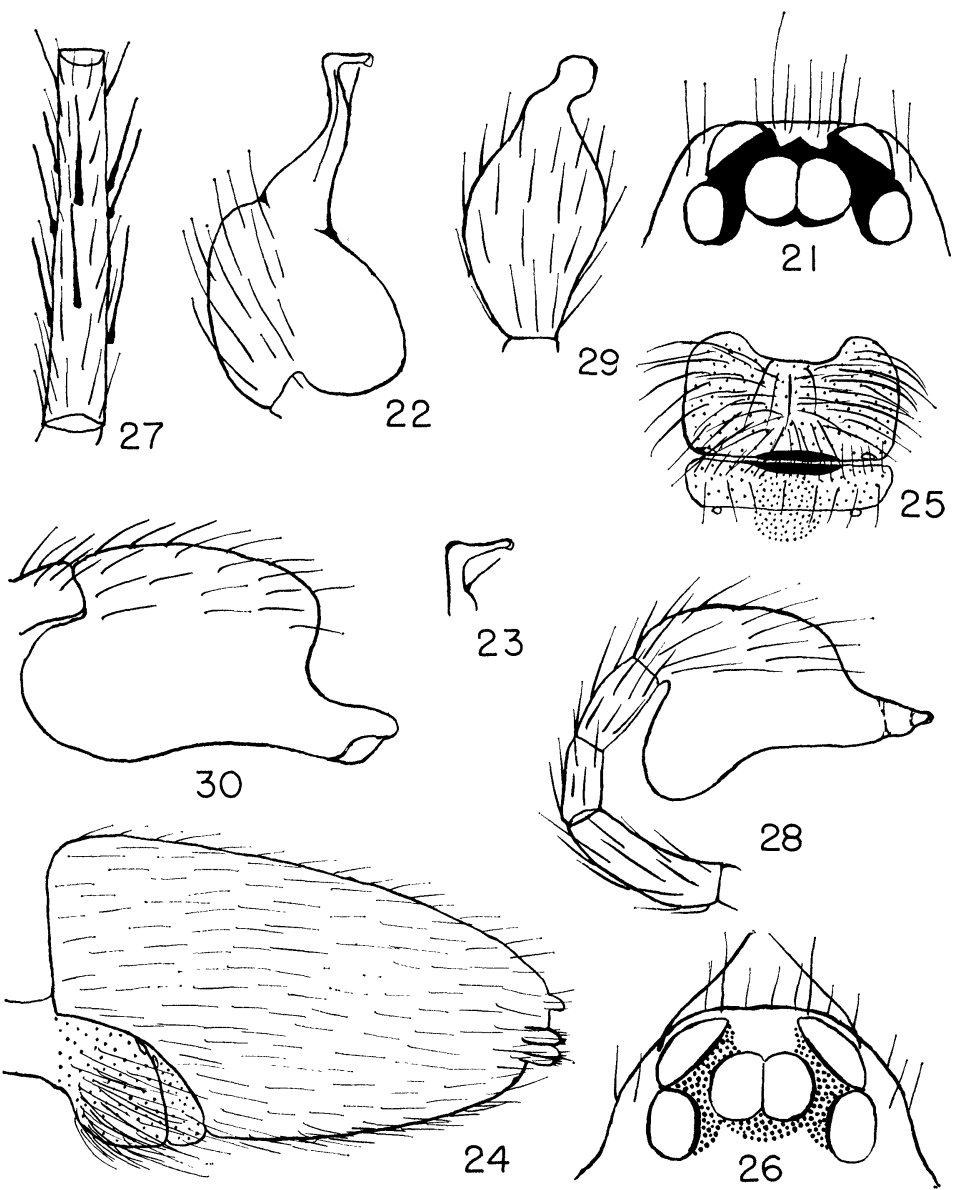

Figs. 21-25. Oonops endicus sp. nov. Fig. 21. Eyes of male holotype from above. Fig. 22. Left male palpal tarsus; prolateral view. Fig. 23. Tip of left embolus; slightly different view. Fig. 24. Abdomen of described female paratype; left lateral view. Fig. 25. Epigynal area of described female paratype. Figs. 26-30. Oonops gertschi sp. nov. Fig. 26. Eyes of male holotype from above. Fig. 27. Right fourth tibia of paratype male; dorsal view. Fig. 28. Left palp of holotype; prolateral view. Fig. 29. Left palpal tarsus of holotype; dorsal view. Fig. 30. Right palpal tarsus; retrolateral view. 
wise essentially as in male. Eyes: ratio of eyes ALE : PME : PLE $=7: 6: 6$; otherwise essentially as in male. Chelicerae, maxillae and lip without special modifications and typical of the genus. Sternum: slightly lobed opposite coxae; each slight lobe bears a cluster of stiff bristles; longer than wide in ratio of nearly $6: 5$; fourth coxae separated by nearly their width; otherwise essentially as in male. Legs: 4123 in order of length as in male; only an occasional spine on first and second legs but third and fourth legs bear several fairly robust spines on tibiae and metatarsi; trichobothria also observed on tibiae and metatarsi. Abdomen: ovoid; scuta much clearer than in male; epigastric scutum with a pronounced swelling (Fig. 24) ; epigynal area essentially as shown in Figure 25. Color in alcohol: in general, essentially as in male; scutal regions more clearly outlined because of stronger chitinization; pigment in ocular region black and reddish mixed; abdomen with a fairly clear reticulation in addition to the basically whitish or very pale yellowish coloration.

Diagnosis. This appears to be another species more or less closely related to Oonops anoxus from the Panama Canal Zone. The features of the male palp and the distinctive epigynal area of the female quite definitely establish it as a new species.

Records. The described female paratype was, apparently, collected with the male holotype. Numerous paratypes of both sexes are in the collection from the region in which the holotype was taken and all were collected by Dr. W. J. Gertsch, M. A. Cazier and C. and $\mathrm{P}$. Vaurie.

\section{Oonops gertschi sp. nov.}

Figures 26-30

Holotype. The male holotype is from So. Bimini, Bahama Islands, May, I95I ; collected by Dr. W. J. Gertsch and M. A. Cazier. The species is named after Dr. W. J. Gertsch, formerly Curator of Arachnida, American Museum of Natural History, New York City and will be deposited in that institution.

Description. Total length $1.47 \mathrm{~mm}$. Carapace nearly $0.7 \mathrm{~mm}$ long; $0.52 \mathrm{~mm}$ wide opposite interval between second and third coxae where it is widest; nearly $0.27 \mathrm{~mm}$ tall; gently raised just behind PME and then nearly level to beginning of moderately steep posterior declivity opposite interval between third and fourth coxae (the holotype is very fragile with boundaries of parts often indistinct). Eyes: six as usual in a moderately compact group; posterior row only a little wider than anterior row and occupies a little more than seventenths of width of carapace at that level (Fig. 26) ; outlines some- 
what indistinct. Ratio of eyes ALE : PME : PLE = nearly 6 : $5: 5$. ALE separated from one another by nearly five-sevenths of their diameter; contiguous to PLE at one point and separated from PME by a broad line. PME contiguous to one another for fully one-third of their circumference and separated from PLE by a broad line. Clypeus very narrow and with ventral border very indistinct; several slender spines on clypeus and adjoining regions. Chelicerae, maxillae and lip apparently all typical of males of the genus and without observed special modifications. Sternum: recorded from a paratype because of curled, fragile legs of holotype ; moderately convex; longer than wide in ratio of nearly $4: 3$; with faintly indicated marginal grooves and lobes; extended between fourth coxae which are separated by a little more than their width. Legs: 4 I23 in order of length; spines are fairly numerous on third and fourth legs (Fig. 27 ) ; trichobothria observed but number and placement not determined. Palp: tarsus quite distinctive (Figs. 28-30); other segments typical of males of the genus and without special modifications. Abdomen: slender ovoid; nearly typical of males of the genus in general; ventral scuta indiscernible. Color in alcohol: cephalothorax, legs and mouth parts very light yellowish with little variation; only a moderate amount of black pigment in ocular area; a few paratypes show almost no pigment in ocular area and eyes are nearly indiscernible; abdomen nearly pure white.

Diagnosis. This species appears to be most closely related to Oonops vestus sp. nov. from Trinidad, W. I. The features of the male palp together with several other minor features definitely establish it as a new species. No palpal tarsus with this type of termination has been seen thus far in this study of the genus Oonops.

Records. One paratype male was taken in May, I95 I on So. Bimini, Bahama Ids. by Dr. W. J. Gertsch and M. A. Cazier; five males were taken in June, I95I on the same island by C. and P. Vaurie. The female is unknown.

Oonops ronoxus sp. nov.

Figures 3I-34

Holotype. The male holotype is from St. Croix, U. S. Virgin Islands, Sept. I, 1966. The name of the species is an arbitrary combination of letters.

Description. Total length nearly $\mathrm{I} .34 \mathrm{~mm}$, including extended spinnerets. Carapace nearly $0.55 \mathrm{~mm}$ long; nearly $0.4 \mathrm{~mm}$ wide opposite second coxae; nearly $0.26 \mathrm{~mm}$ tall; considerably narrowed shortly behind PLE; with profile essentially as shown in Figure 31. Eyes: six in two rows as usual in the genus (Fig. 32). Posterior 


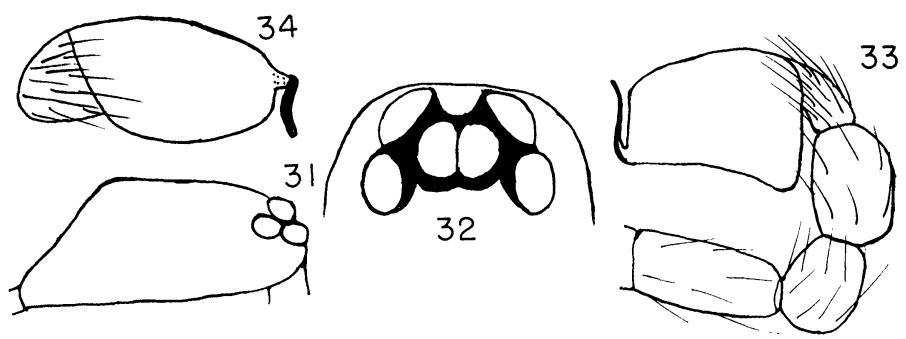

Figs. 31-34. Oonops ronoxus sp. nov. Fig. 31. Carapace of holotype; right lateral view. Fig. 32. Eyes of holotype from above. Fig. 33. Left palp of holotype; retrolateral view. Fig. 34. Left palpal tarsus; nearly dorsal view.

row distinctly recurved and occupies about eight-elevenths of width of carapace at that level. Very little difference in size of eyes but with ALE slightly the largest. ALE separated from one another by nearly three-fifths of their long diameter; barely separated from PLE and separated from PME by a broad line. PME contiguous to one another for nearly one-third of their circumference and separated from PLE by a broad line. Height of clypeus appears to be somewhat less than the radius of ALE. Chelicerae, maxillae and lip: apparently quite typical of males of the genus with no special modifications observed. Sternum: moderately convex; surface smooth and with few hairs; longer than wide in ratio of nearly $4: 3$; extended between bases of fourth coxae which are separated by nearly their width; posterior end with a small cluster of erect, stiff hairs. Only fourth legs retained; these are moderately long and slender; apparently with a few slender, transparent spines. Palp: quite distinctive; essential features shown in Figures 33-34; the cymbium is unusually short. Abdomen: somewhat taller than cephalothorax; no ventral or epigastric scutum observed; entire abdomen soft and with little chitinization. Color in alcohol: with a moderate amount of black pigment in ocular region; all other parts of cephalothorax, legs and mouth parts light yellowish with little variation; abdomen almost white throughout.

Diagnosis. The general features of the carapace and eyes seem to ally this species with such already recognized species as Oonops persitus sp. nov. from the Panama Canal Zone. The distinctive features of the male palp, especially the tarsus, definitely establish it as a new species. 
Records. One male paratype was taken with the holotype. Another male was taken on Virgin Gorda, British Virgin Islands in August, 1966. An immature female was taken on Virgin Gorda during the same period but its status is uncertain.

\section{BIBLIOGRAPHY}

Banks, NATHAN

1902. Some Spiders and Mites from the Bermuda Islands. Trans. Connecticut Acad. Sci. 11, pt. 1, p. 269, fig. 1.

Bonnet, Pierre

1958. Bibliographia Araneorum. Toulouse. 2(4).

Bryant, Elizabeth

1942. Notes on the Spiders of the Virgin Islands. Bull. Mus. Comp. Zool., 89(7): 317-363, 40 figs.

Chickering, A. M.

1971. The Genus Oonops (Araneae, Oonopidae) in Panama and the West Indies. Part 1. Psyche, 77.

GER'TSCH, W. J.

1936. Further Diagnoses of New American Spiders. Amer. Mus. Novit., No. 852: 1-27, 4 pls.

Petrunkevitch, Alexander

1926. Spiders from the Virgin Islands. Connecticut Acad. Arts and Sci. 28: 23-78, 28 figs.

1929. The Spiders of Porto Rico. Pt. 1. Trans. Connecticut Acad. Arts and Sci. 30:7-158, 150 figs.

ROEWER, C. Fr.

1942. Katalog der Araneae. 1: 1-1040.

Simon, E.

1892- Histoire naturelle des Araignées. Deuxième Édition.

1903. 2 vols. Paris: Librarie Encyclopédique de Roret. 

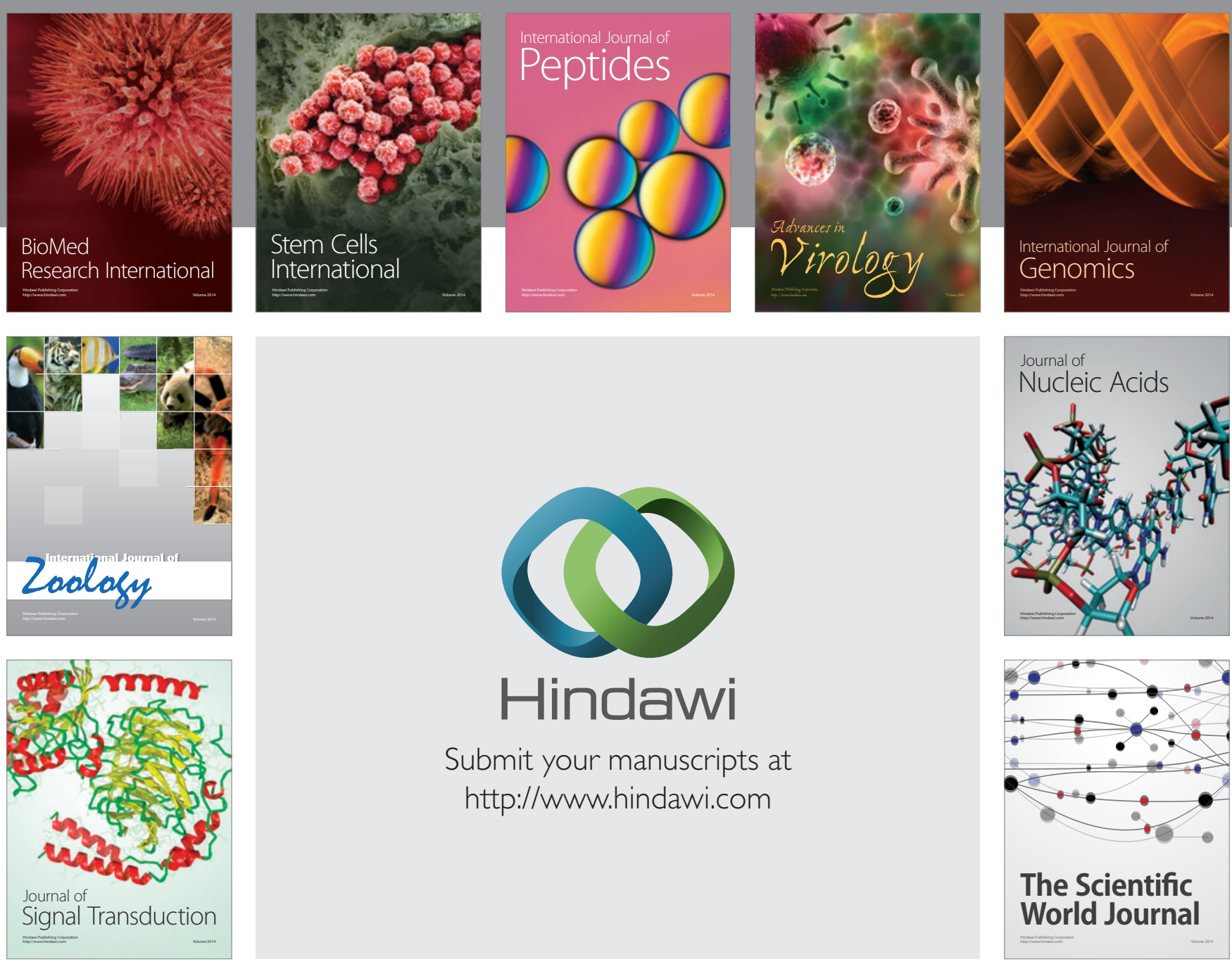

Submit your manuscripts at

http://www.hindawi.com
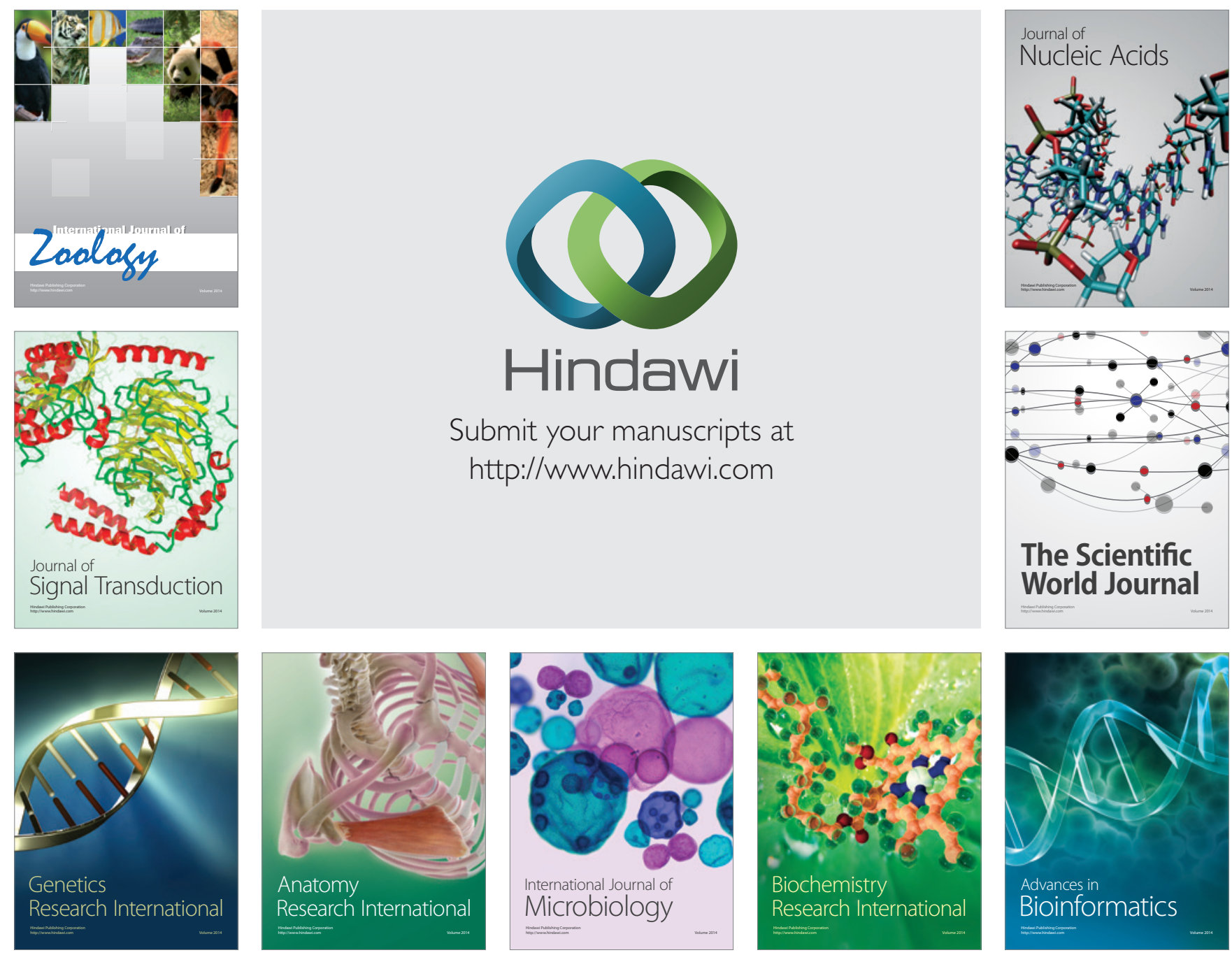

The Scientific World Journal
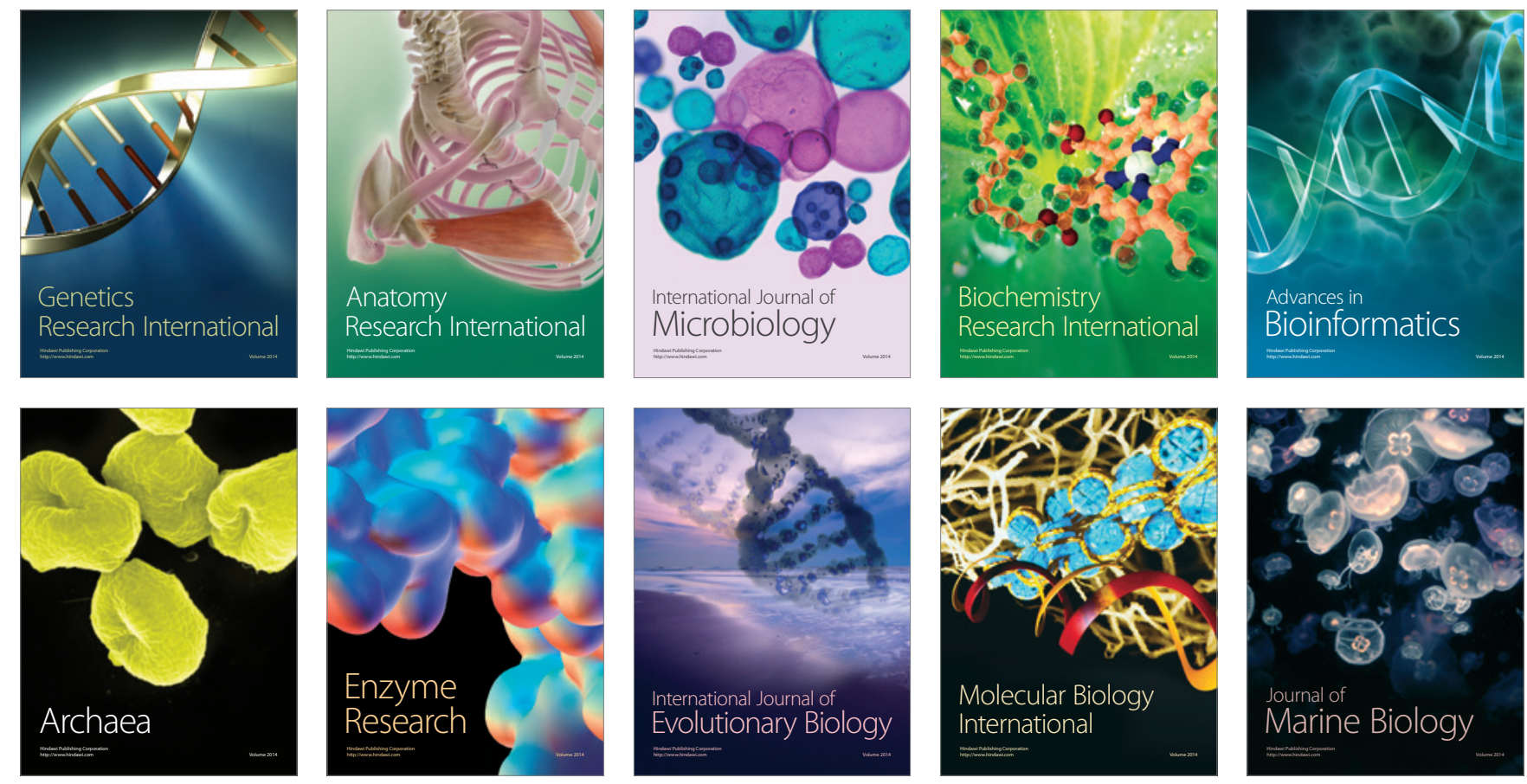